\title{
Thermal Analysis of Parabolic Dish Receiver System and Energy Analysis by using Energy 3D Software
}

\author{
Shravan Mandhare ${ }^{\# 1}$, Ramola Sinha ${ }^{* 2}$ \\ 1M.Tech Student, 2 Asst. Prof., \\ Department of Mechanical Engineering, \\ K. J. Somaiya College of Engineering
}

\begin{abstract}
Parabolic Dish (PD) is one of the most efficient Concentrating Solar Technology (CSP) technologies that convert solar energy into thermal energy and electricity. Parabolic Dish has shown the highest efficiency and can achieve up to $750^{\circ} \mathrm{C}$ temperature and has emerged as one of the most reliable and efficient Renewable Energy (RE) technology. However, the performance evaluation of the parabolic dish by using experimental approach is costly and time consuming.A parametric study of a parabolic dish receiver system design is analyze in order to determine the best configuration to achieve an optimal system performance in this work. A parabolic dish receiver system is designed based on the analysis for a process heat application. Rim angle is an important parameter which determine the imaging and non-imaging diameter of the flux radiation for selecting the types of receiver. It shows that the optimum parameter of the parabolic dish is important to achieve the high intensity at the focus point of the receiver. Energy 3D software is to be optimized energy analysis for daily, monthly and annual distribution as discussed in the software program with input parameters of rim radius, focal length of parabolic dish.
\end{abstract}

Keywords : Parabolic dish, receiver, parabola geometry, energy analysis by energy $3 D$ software

\section{INTRODUCTION}

Renewable energies have gained more and more interest in recent years for numerous reasons such as the increase of fossil fuels prices, the high concentration of $\mathrm{CO} 2$ emissions, the need to reduce greenhouse gas emissions and the growing worldwide energy consumption. One of the most important renewable energy sources available today is solar energy. It is a very abundant clean energy source that emits no greenhouse gases. The concentrating solar collectors are the most developed technology for the use of solar energy owing to their higher temperatures in the focal zone. The most well known technologies for concentrating solar collectors are solar power towers, solar parabolic dishes, parabolic trough collectors and linear Fresnel reflectors.

Concentrating solar collector system are line focusing and point focusing, parabolic dish collector system is the point focusing 2-D axis tracking system. The main function of the parabolic dish collector (PDC) system is to be absorbed solar energy which is received from the sun as a source, collect all the concentrating rays at the collector position then this concentrator system delivered rays towards the receiver position. Heat losses its takes place at the receiver position there is convection losses, radiation losses and the reflection loss at the reflecting surface area. Neglecting the conduction loss. difference between the concentrator heat and heat loss by the receiver is to be net heal calculation at receiver position ,and that heat is to be utilized for the process heat application. Energy 3D software is used for the site location with respect to energy receiving from the parabolic dish. Energy estimation by daily, monthly and annual distribution can be calculated.

Joseph Stalin ..et al the author study on point focusing solar concentrating system with the system of solar tower power plants. He study on the methodology of receiver design under the external receiver design also examine the number of tube and panel design. In this research the author finds nusselt number correlation with respect to Reynolds number this finding for the losses on the receiver.

Evengelos Bellosa and Erion Bousi study on optical and thermal performance on cavity receiver with different shape of cavity receiver under the high thermal fluid flow. The author finds the best optical efficiency under the cylindrical cavity receiver for the therminol fluid.

V. Thirunavukkarsul and M. Cheralathan the authors study on experimental study on heat losses from the external receiver type solar parabolic dish collector. Under this research author used water as heat transfer fluid for the heating application of solar cooker thermal design by using the helical coil for reduce the heat loss. This external receiver system is cheap in cost.

\section{EXPERIMENTAL SETUP}

Parabolic dish receiver system is used for the heating application that is solar water heater. Solar water heater is designed with respective of parameters aperture diameter and absorber / receiver length is equal to $3.82 \mathrm{~mL}_{\text {abs }} / \mathrm{d}_{\mathrm{abs}}=1$ and the diameter of receiver is $0.54 \mathrm{~m}$, focal length of the parabolic dish is $1.326 \mathrm{~m}$. consider the concentrator ratio is to be 10 , with respect to concentration ratio rim angle is to be determined as $71.57^{\circ}$. The receiver is coated with black paint which has effective absorptivity and emissivity is 0.95 and 0.02 respectively.

Working fluid is circulated to the absorber tube with help of pump or compressor, fluid should have high temperature dependent and measured in terms of mass flow rate $\mathrm{kg} / \mathrm{s}$ or $\mathrm{kg} / \mathrm{hr}$. During circulation it gains heat in the absorber tube and 
comes back in the storage tank. The HTF is then recirculating again and again through the absorber tube throughout the whole day. Selection criteria for heat transfer fluid [20]

Temperature range, viscosity, density, thermal conductivity, High and low temperature applications, Cost, stability, Environmental impact, toxicity, corrosiveness. On the basis of design parameters of CSP once temperature range criteria is known, then (HTF) fluid easily be chosen according to conditions.

There are two types of receiver designs one is external type receiver and other is internal type receiver that is cavity receiver. The main factor influencing its design is its ability to accept the large and variable heat flux which results from the concentration of the solar radiation by the point focussing parabolic dish collector (PDC) system. Rim angle is also important parameter to achieve maximum flux irradiation at this particular point. $\frac{f}{d}$ ratio is to be key point of to determine the type of receiver with the help of rim angle. The paraboloid with small rim angles has the focal point and receiver at large distance from the surface of concentrator. The paraboloid with rim angle smaller than $50^{\circ}\left(\varphi<50^{\circ}, 48^{\circ}\right)$ is used for cavity receivers while paraboloids with large rim angles are most appropriate for the external volumetric receivers (central receiver solar systems).

Importance of using external type receiver for point focussing parabolic dish receiver system with the water as working fluid. Receiver losses are very crucial in the format of calculating energy analysis or heat analysis at receiver position. The concentrator heat is reflected towards the receiver position that same case losses are also happened convection with the natural and forced convection affected by wind speed and radiation heat loss with absorptivity and emittance of the material. Minimize the heat loss to achieve the maximum heat analysis at receiver position so that heat is supposed to be used for the heat storage application.

All the thermophysical properties of air and water to be consider for the thermal losses calculation

\section{Theory of Experimental Parameters \& Experimentation:}

\section{ESTIMATION OF HEAT LOSSES}

The total thermal loss of the receiver $\left(Q_{\text {loss }}\right)$ includes three types of losses, as shown in figure 1:

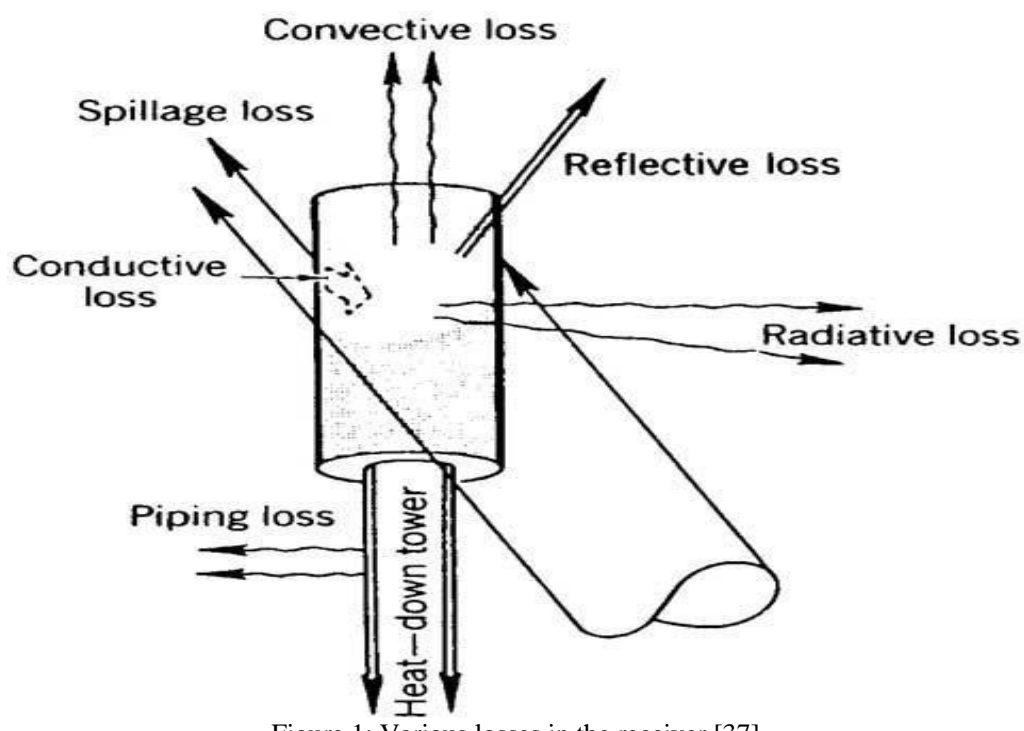

Figure 1: Various losses in the receiver [37]

\section{EXTERNAL RECEIVER}

In case of external receivers, the entire absorber area is exposed to the surroundings. Hence, there are higher thermal losses from the receiver to the surroundings compared to cavity receivers [22]. The main thermal losses are convection and radiation heat loss.

Thermal losses are divided in three categories :-

1. Convection heatloss

2. Radiation heatloss

3. Conduction heat loss

\section{ESTIMATION OF CONVECTION HEAT LOSS}

For cylindrical receivers, convective heat transfer is influenced by both natural and forced convection. Hence, mixed convection is usually considered [43]. According to Cengel [15], the value $\mathrm{m}$ lies between 3 and 4.The value close to 3 suits better for vertical surfaces and the larger values are suited for horizontal surfaces. 
The heat transfer coefficient for convective heat loss for cylindrical receiver as follows:-

$$
h_{\text {mix }}=\left(h_{\text {nat }}^{m}+h_{\text {for }}^{m}\right)^{\wedge} \frac{1}{m}
$$

$h_{\text {nat }}=$ heattransfercoefficientduetonaturalconvection $\left(\mathrm{w} / \mathrm{m}^{2} \mathrm{k}\right)$

$h_{\text {for }}=$ heattransfercoefficientduetoforcedconvection $\left(\mathrm{w} / \mathrm{m}^{2} \mathrm{k}\right)$

\section{Thermal analysis to follow natural convection losses on receiver}

Here in analysis of thermal losses, considering the temperature range of inlet $\left(T_{i n}\right)$ is to be $25^{\circ} \mathrm{C}, 30^{\circ} \mathrm{CAnd} 35^{\circ} \mathrm{C}$ respectively and outlet temperature $\left(T_{\text {out }}\right)$ be $90^{\circ} \mathrm{C}, 95^{\circ} \mathrm{C}, 100^{\circ} \mathrm{C}$ respectively .consider the ambient temperature as $\left(T_{a m b}\right)$ is $27^{\circ} \mathrm{C}$. All fluid temperature are calculated at this film temperature,

$$
\begin{gathered}
\therefore T_{f m}=\frac{T_{s, a v g}+T_{a m b}}{2} \\
\therefore T_{s, \text { avg }}=\left(\frac{T_{s, \text { out }}^{4}+T_{s, \text { in }}^{4}}{2}\right)^{1 / 4}
\end{gathered}
$$

Now, find the grashoff number for natural convection, (reference)

$$
\therefore G r=\frac{g \times \beta \times\left(T_{s, a v g}-T_{a m b}\right) \times L_{r e c}{ }^{3}}{v^{2}}
$$

- $g=$ acceleration due to gravity, $\left(\frac{m}{s^{2}}\right)$

- $\beta=$ volumetric expansion coeffiecient,$(1 / K)$

- $T_{\text {s,avg }}=$ average surface temperture of the receiver,$K$

- $T_{a m b}=$ ambient temperature, $K$

- $\quad L_{r e c}=$ height of the receiver,$m$

- $v=$ kinematic viscosity, $\mathrm{m}^{2} / \mathrm{s}$

Then find the prandlts number by using formula ,

$$
\therefore \operatorname{Pr}=\frac{\mu \cdot C p}{k}
$$

- $\quad \mu=$ dynamic viscosity, $\mathrm{kg} / \mathrm{ms}$

- $\quad C p=$ specific heat $\mathrm{J} / \mathrm{kgK}$

- $\quad k=$ thermal conductivity, $W / m K$

Determine the Rayleigh number, is the product of grashoff number and prandlts number

$$
\therefore R a=G r \times P r
$$

Obtaining the value of Rayleigh number calculate the nusselt number by using following equation,

$$
\therefore N u_{\text {nat }}=\left(0.825+\frac{0.387 R a^{1 / 6}}{\left.\left(1+\frac{0.492}{P r}\right)^{9 / 16}\right)^{8 / 27}}\right)^{2}\left(\mathrm{Ra}<10^{12}\right)
$$

Then to find the $h_{\text {nat }}$ by using following formula

$$
\therefore N u_{n a t}=\frac{h_{n a t} \times L_{r e c}}{k}
$$

Thermal losses by forced convection on receiver

Reynolds number to be calculated by using following formula,

$$
\therefore R e=\frac{\mu_{\text {wind }} \times D_{r e c}}{v}
$$


- $\quad \mu_{\text {wind }}=$ wind velocity, $\mathrm{m} / \mathrm{s}$

- $D_{\text {rec }}=$ diameter of receiver

- $\quad v=$ kinematic viscosity, $\mathrm{m}^{2} / \mathrm{s}$

Then have to determined nusselt number by forced convection,

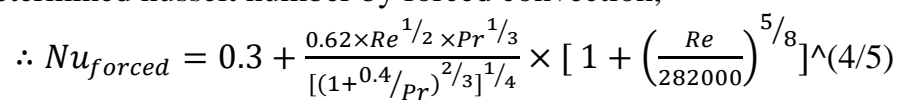

Then to find the $h_{\text {forced }}$ by using following formula

$$
\therefore N u_{\text {forced }}=\frac{h_{\text {forced }} \times L_{\text {rec }}}{k}
$$

After getting the value $h_{\text {nat }} \& h_{\text {forced }}$ put these value in equation (1) and getting the value of $h_{\text {mix }}$, considering $\mathrm{m}$ is 3 [36] Heat loss convection for external receiver is calculated as follows:-

$$
\therefore Q_{\text {loss conv }}=h_{\text {mix }} \times A_{\text {rec }} \times\left(T_{s, a v g}-T_{a m b}\right)
$$

Estimation of Radiation Losses :-

The heat loss by radiation process for external receiver can be calculated by the stefen boltzman law, the external receiver is coated with the black coating

$$
\begin{gathered}
\therefore Q_{\text {loss rad }}=\sigma \times \varepsilon_{\text {eff }} \times A_{\text {proj }} \times\left(T_{s, a v g}{ }^{4}-T_{a m b}{ }^{4}\right) \\
\therefore \varepsilon_{\text {eff }}=\frac{\varepsilon}{\varepsilon+(1-\varepsilon) \times \frac{2}{\pi}}
\end{gathered}
$$

- $\sigma=$ boltzman constant i.e $5.67 \times 10^{-8} \mathrm{w} / \mathrm{m}^{2} \mathrm{~K}^{4}$

- $\quad \varepsilon_{\text {eff }}=$ effective emmissivity of the receiver

- $\quad A_{\text {proj }}=$ projected area of the receiver $(\pi D L)$

By using these equation we get the effective emittance for black coating here $\varepsilon=0.015$ [38] From these equation we get the total heat loss by the radiation on external receiver

Estimation of reflection heat loss on external receiver:-

The part of radiation which is reflected away from the receiver surface is called reflective heat loss it can be calculated by the absorptance of receiver coating.

$$
\begin{aligned}
\therefore Q_{\text {lossreflection }} & =\left(1-\alpha_{\text {eff }}\right) \times Q_{\text {therreceiver }} \\
\therefore \alpha_{\text {eff }} & =\frac{\alpha}{\alpha+(1-\alpha) \times \frac{2}{\pi}}
\end{aligned}
$$

- $\alpha_{\text {eff }}=$ effectiveabsorptance

- $Q_{\text {therreceiver }}=$ thermalheatatreceiver $(m C p \Delta T)$

absorptance $\alpha$ consider to be 0.92.[38]

So getting all thermal losses on receiver by convection, radiation and reflection to be derived,

$$
\therefore Q_{\text {loss total }}=Q_{\text {loss conv }}+Q_{\text {loss rad }}+Q_{\text {loss reflection }}
$$

Case 1:-

\section{RESULTS AND DISCUSSION}

Here all the input parameters are the same whichever concerned as above calculation

Constant parameter:- $T_{\text {in }}=25^{\circ} \mathrm{C}, T_{\text {out }}=100^{\circ} \mathrm{C}, T_{\text {amb }}=27^{\circ} \mathrm{C}$

Varying parameter:- velocity of air -3 to $5 \mathrm{~m} / \mathrm{s}$ 
Table 1efficiency rate with respect to velocity of air in $(\mathrm{m} / \mathrm{s})$

\begin{tabular}{|c|c|c|c|c|c|c|c|c|}
\hline va $(\mathrm{m} / \mathrm{s})$ & hnat (W/m2K) & hfor $(\mathrm{W} / \mathrm{m} 2 \mathrm{~K})$ & Qconv $(\mathrm{W})$ & Qrad $(\mathrm{W})$ & Qref $(\mathrm{W})$ & Qlost $(\mathrm{W})$ & Qavail $(\mathrm{W})$ & $\eta(\%)$ \\
\hline 3.00 & 4.85 & 10.24 & 403.89 & 6.71 & 220.22 & 630.81 & 4199.84 & 84.98 \\
\hline 3.50 & 4.85 & 11.34 & 443.79 & 6.71 & 220.22 & 670.72 & 4199.84 & 84.03 \\
\hline 4.00 & 4.85 & 12.42 & 483.00 & 6.71 & 220.22 & 709.92 & 4199.84 & 83.10 \\
\hline 4.50 & 4.85 & 13.46 & 521.55 & 6.71 & 220.22 & 748.47 & 4199.84 & 82.18 \\
\hline 5.00 & 4.85 & 14.49 & 559.50 & 6.71 & 220.22 & 786.43 & 4199.84 & 81.27 \\
\hline
\end{tabular}

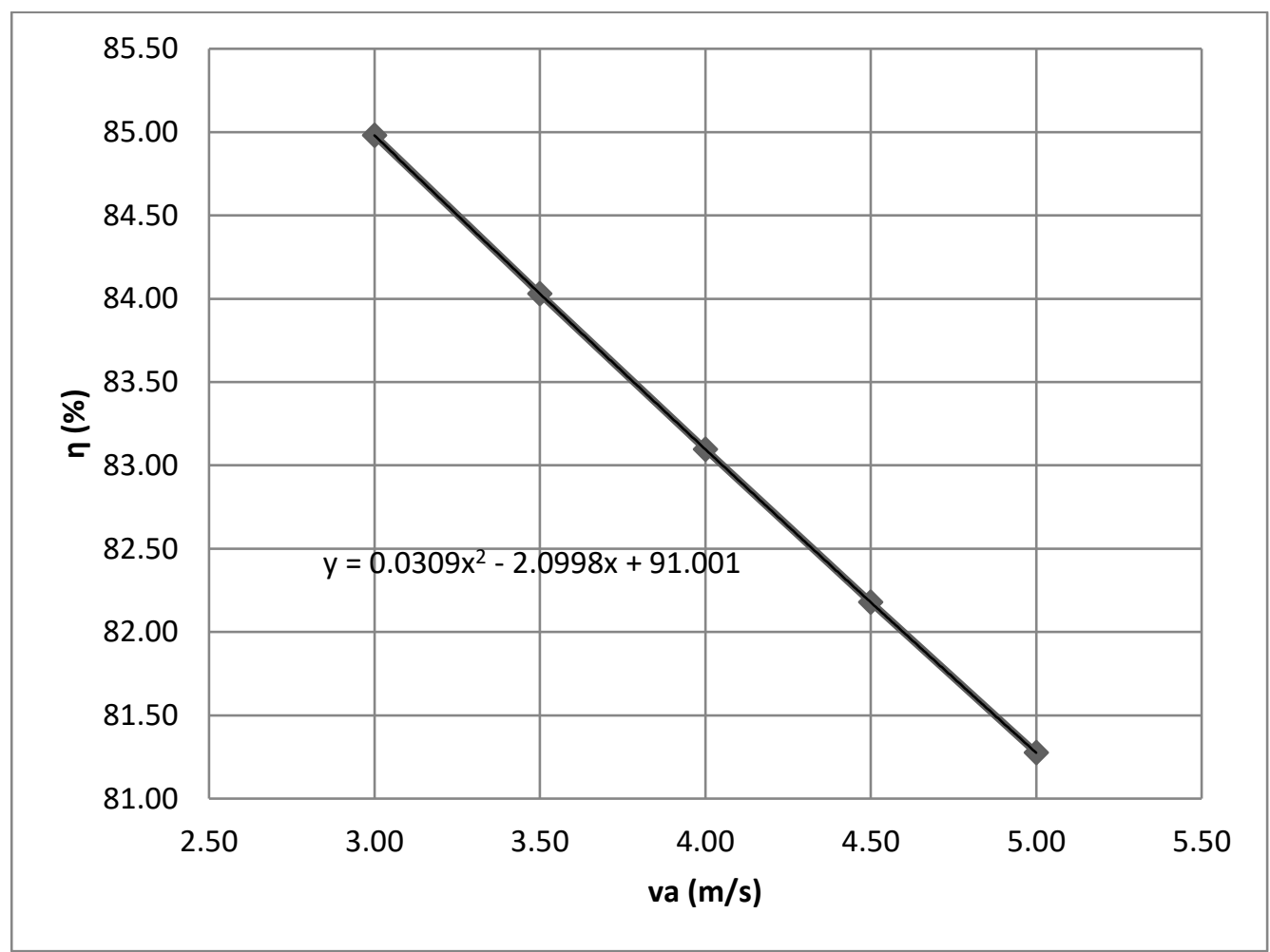

Figure 2 shows the efficiency rate graph with respect to velocity of air

Case 2 :-

Constant parameter $-T_{\text {out }}=100^{\circ} \mathrm{C}, T_{a m b}=27^{\circ} \mathrm{C}$ and velocity of air $-3 \mathrm{~m} / \mathrm{s}$

Varying parameter $-T_{\text {in }}=25^{\circ} \mathrm{C}$ to $35^{\circ} \mathrm{C}$

Table 2 shows the inlet temperature variation on efficiency rate

\begin{tabular}{|c|c|c|c|c|c|c|c|c|}
\hline$T_{\text {in }}\left({ }^{\circ} \mathrm{C}\right)$ & $\begin{array}{c}\text { hnat } \\
(\mathrm{W} / \mathrm{m} 2 \mathrm{~K})\end{array}$ & hfor $(\mathrm{W} / \mathrm{m} 2 \mathrm{~K})$ & Qconv $(\mathrm{W})$ & Qrad $(\mathrm{W})$ & Qref $(\mathrm{W})$ & Qlost $(\mathrm{W})$ & Qavail $(\mathrm{W})$ & $\eta(\%)$ \\
\hline 25.00 & 4.85 & 10.24 & 403.89 & 6.71 & 220.22 & 630.81 & 4199.84 & 84.98 \\
\hline 26.00 & 4.86 & 10.23 & 407.16 & 6.77 & 217.36 & 631.28 & 4145.34 & 84.77 \\
\hline 27.00 & 4.87 & 10.23 & 410.44 & 6.84 & 214.50 & 631.78 & 4090.78 & 84.56 \\
\hline 28.00 & 4.88 & 10.23 & 413.76 & 6.90 & 211.63 & 632.29 & 4036.17 & 84.33 \\
\hline 29.00 & 4.89 & 10.23 & 417.09 & 6.97 & 208.77 & 632.83 & 3981.51 & 84.11 \\
\hline 30.00 & 4.90 & 10.23 & 420.45 & 7.04 & 205.90 & 633.39 & 3926.79 & 83.87 \\
\hline 31.00 & 4.91 & 10.23 & 423.83 & 7.10 & 203.03 & 633.97 & 3872.04 & 83.63 \\
\hline 32.00 & 4.92 & 10.23 & 427.24 & 7.17 & 200.15 & 634.57 & 3817.23 & 83.38 \\
\hline 33.00 & 4.93 & 10.22 & 430.67 & 7.24 & 197.28 & 635.19 & 3762.37 & 83.12 \\
\hline 34.00 & 4.94 & 10.22 & 434.13 & 7.31 & 194.40 & 635.84 & 3707.47 & 82.85 \\
\hline 35.00 & 4.95 & 10.22 & 437.60 & 7.38 & 191.52 & 636.50 & 3652.52 & 82.57 \\
\hline
\end{tabular}




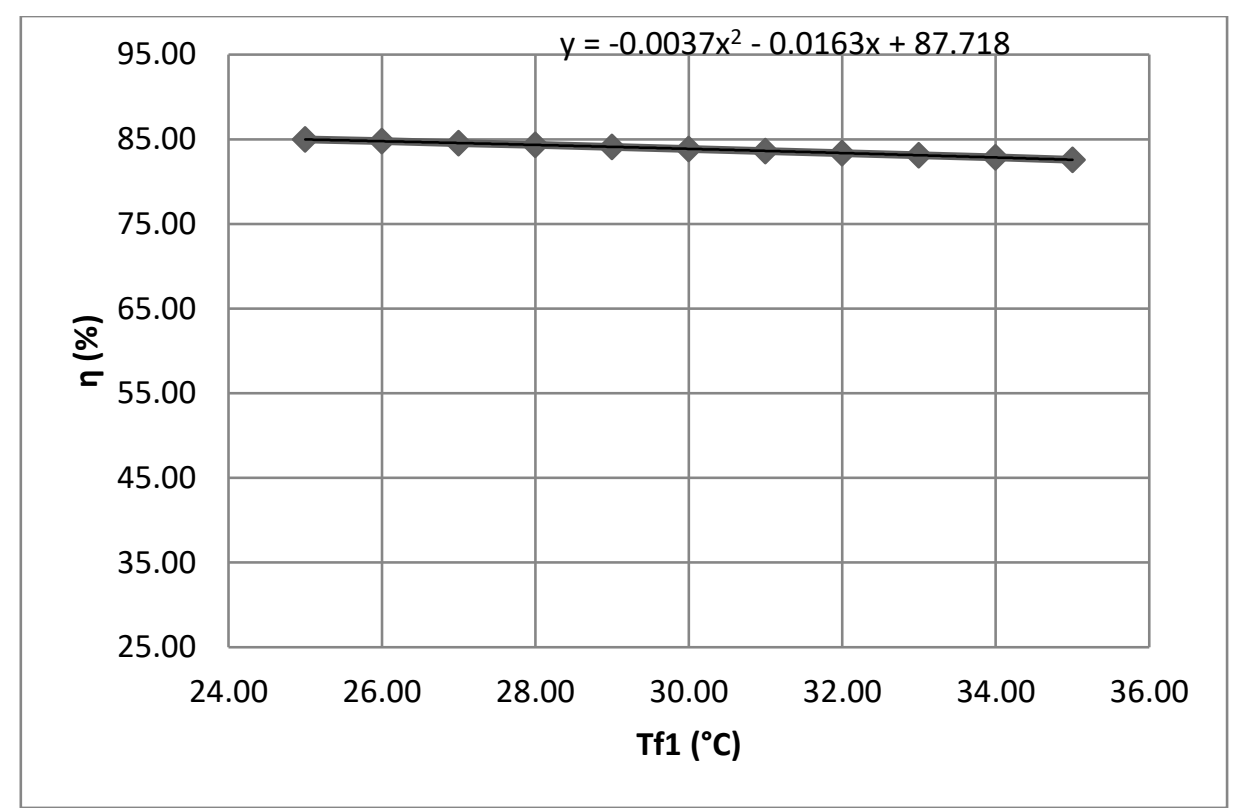

Figure 3 shows the variation of inlet temperature to efficiency

Case 3 :-

Constant parameter $-T_{\text {in }}=25^{\circ} \mathrm{C}, T_{a m b}=27^{\circ} \mathrm{C}$ and velocity of air $-3 \mathrm{~m} / \mathrm{s}$

Varying parameter $-T_{\text {out }}=90^{\circ} \mathrm{C}$ to $100^{\circ} \mathrm{C}$

Table 3 shows the variation of outlet temperature on efficiency rate on receiver

\begin{tabular}{|c|c|c|c|c|c|c|c|c|}
\hline$T_{\text {out }}\left({ }^{\circ} \mathrm{C}\right)$ & hnat (W/m2K) & hfor $(\mathrm{W} / \mathrm{m} 2 \mathrm{~K})$ & Qconv $(\mathrm{W})$ & Qrad (W) & Qref (W) & Qlost (W) & Qavail (W) & $\eta(\%)$ \\
\hline 100.00 & 4.85 & 10.24 & 403.89 & 6.71 & 220.22 & 630.81 & 4199.84 & 84.98 \\
\hline 99.00 & 4.83 & 10.24 & 397.52 & 6.58 & 217.20 & 621.30 & 4142.35 & 85.00 \\
\hline 98.00 & 4.81 & 10.24 & 391.17 & 6.46 & 214.19 & 611.81 & 4084.88 & 85.02 \\
\hline 97.00 & 4.78 & 10.24 & 384.83 & 6.33 & 211.18 & 602.34 & 4027.44 & 85.04 \\
\hline 96.00 & 4.76 & 10.25 & 378.51 & 6.21 & 208.17 & 592.89 & 3970.03 & 85.07 \\
\hline 95.00 & 4.74 & 10.25 & 372.21 & 6.09 & 205.16 & 583.45 & 3912.65 & 85.09 \\
\hline 94.00 & 4.72 & 10.25 & 365.92 & 5.97 & 202.15 & 574.04 & 3855.29 & 85.11 \\
\hline 93.00 & 4.70 & 10.26 & 359.65 & 5.85 & 199.14 & 564.65 & 3797.98 & 85.13 \\
\hline 92.00 & 4.67 & 10.26 & 353.40 & 5.73 & 196.14 & 555.27 & 3740.69 & 85.16 \\
\hline 91.00 & 4.65 & 10.26 & 347.17 & 5.61 & 193.14 & 545.92 & 3683.43 & 85.18 \\
\hline 90.00 & 4.63 & 10.26 & 340.95 & 5.49 & 190.14 & 536.58 & 3626.20 & 85.20 \\
\hline
\end{tabular}

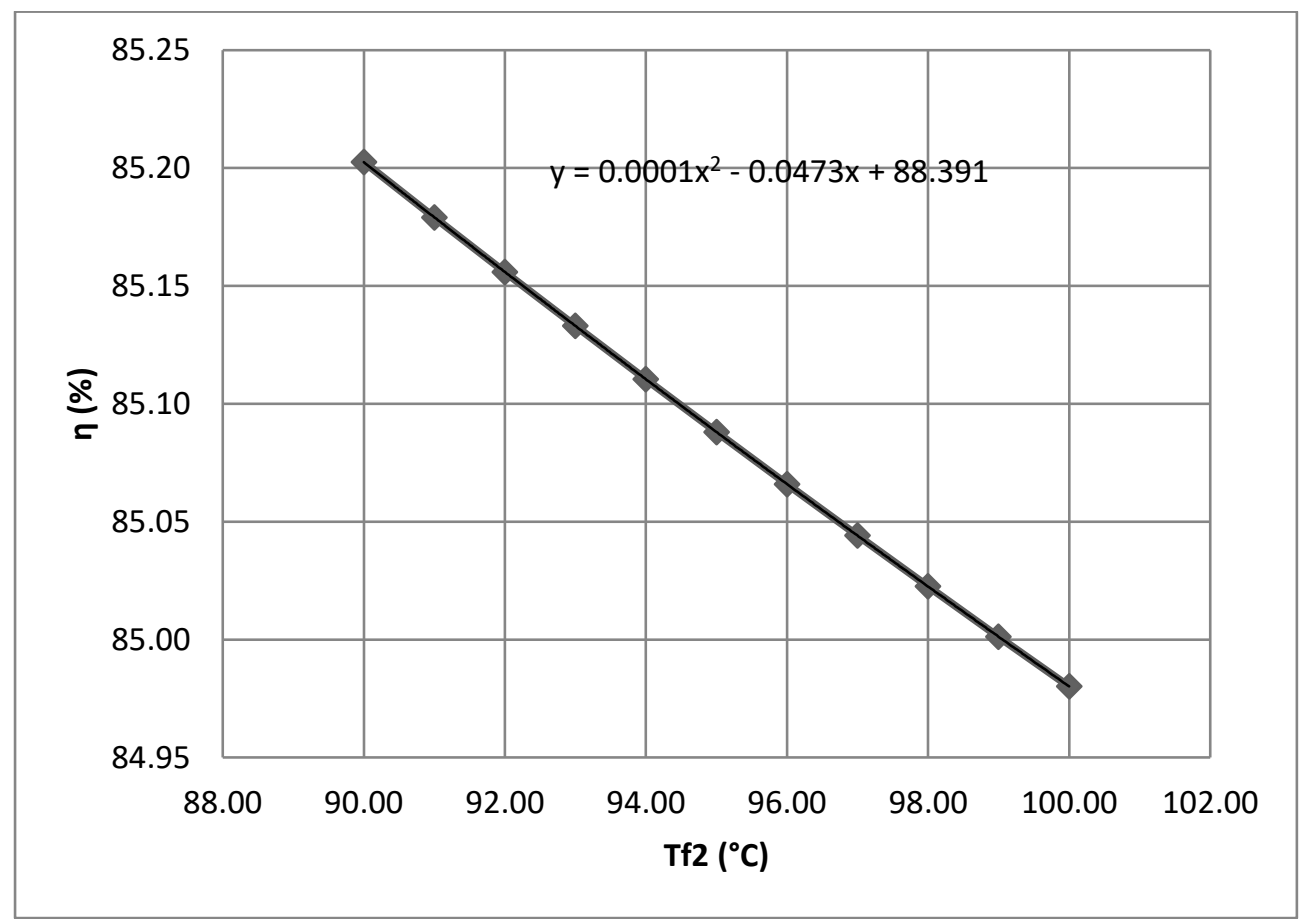

Figure 4 shows the variation of outlet temperature to efficiency 
Case 4 -

Constant parameter $-T_{\text {in }}=25^{\circ} \mathrm{C}, T_{\text {out }}=100^{\circ} \mathrm{C}$ and velocity of air $-3 \mathrm{~m} / \mathrm{s}$

Varying parameter $-T_{a m b}=25^{\circ} \mathrm{C}$ to $35^{\circ} \mathrm{C}$

Table 4 shows the variation of ambient temperature on efficiency rate on receiver

\begin{tabular}{|c|c|c|c|c|c|c|c|c|}
\hline Tamb $\left({ }^{\circ} \mathrm{C}\right)$ & $\begin{array}{c}\text { hnat } \\
(\mathrm{W} / \mathrm{m} 2 \mathrm{~K})\end{array}$ & hfor $(\mathrm{W} / \mathrm{m} 2 \mathrm{~K})$ & Qconv (W) & Qrad (W) & Qref (W) & Qlost (W) & Qavail (W) & $\eta(\%)$ \\
\hline 25.00 & 4.92 & 10.24 & 424.28 & 6.97 & 220.22 & 651.46 & 4199.84 & 84.49 \\
\hline 26.00 & 4.89 & 10.24 & 414.07 & 6.84 & 220.22 & 641.13 & 4199.84 & 84.73 \\
\hline 27.00 & 4.85 & 10.24 & 403.89 & 6.71 & 220.22 & 630.81 & 4199.84 & 84.98 \\
\hline 28.00 & 4.81 & 10.23 & 393.73 & 6.57 & 220.22 & 620.52 & 4199.84 & 85.23 \\
\hline 29.00 & 4.77 & 10.23 & 383.60 & 6.44 & 220.22 & 610.26 & 4199.84 & 85.47 \\
\hline 30.00 & 4.73 & 10.22 & 373.49 & 6.31 & 220.22 & 600.01 & 4199.84 & 85.71 \\
\hline 31.00 & 4.69 & 10.22 & 363.40 & 6.17 & 220.22 & 589.78 & 4199.84 & 85.96 \\
\hline 32.00 & 4.64 & 10.21 & 353.33 & 6.03 & 220.22 & 579.58 & 4199.84 & 86.20 \\
\hline 33.00 & 4.60 & 10.21 & 343.29 & 5.89 & 220.22 & 569.40 & 4199.84 & 86.44 \\
\hline 34.00 & 4.56 & 10.21 & 333.27 & 5.75 & 220.22 & 559.24 & 4199.84 & 86.68 \\
\hline 35.00 & 4.51 & 10.20 & 323.27 & 5.61 & 220.22 & 549.10 & 4199.84 & 86.93 \\
\hline
\end{tabular}

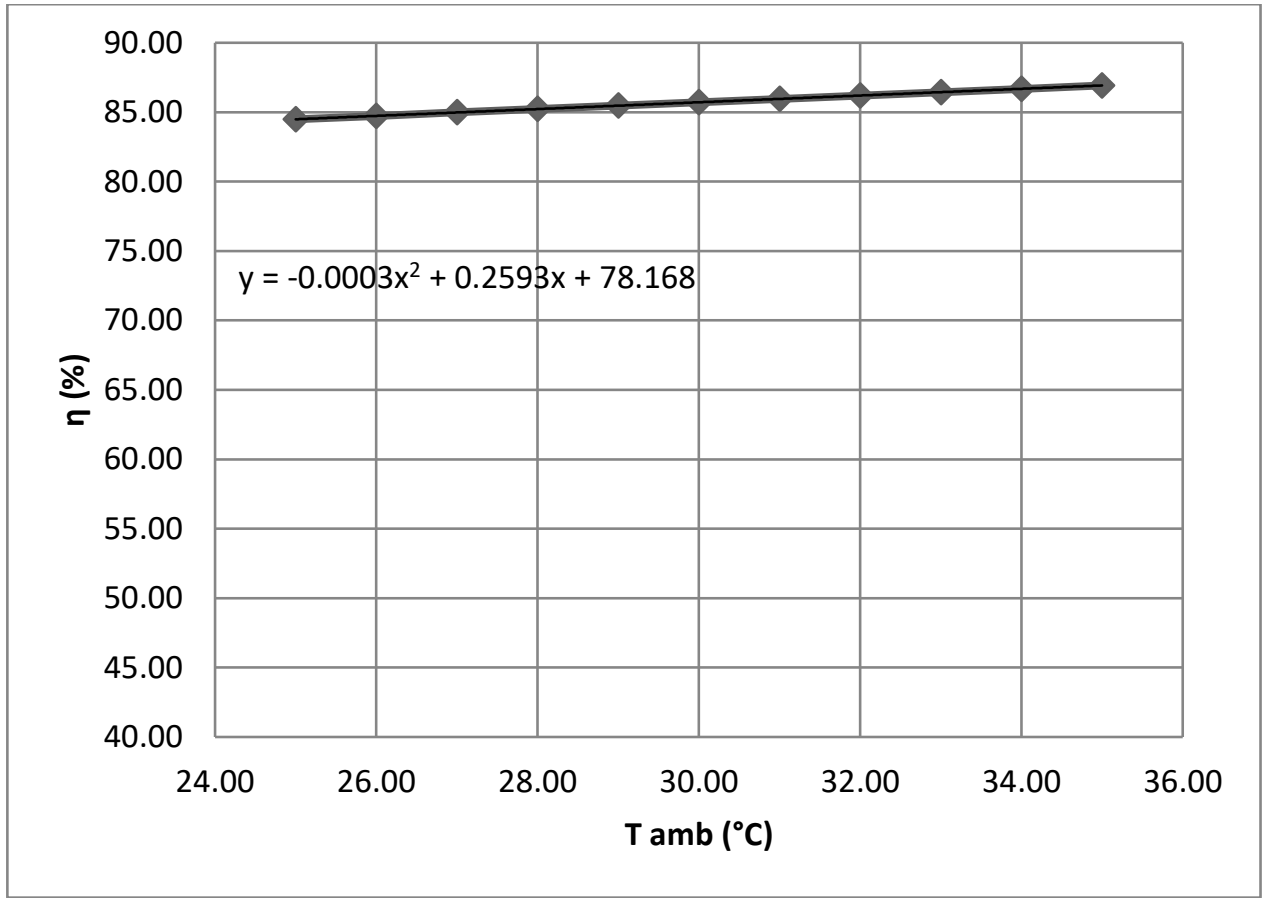

Figure 5 shows the variation of ambient temperature to efficiency

At respective four cases on heat loss at thermal receiver and thermal heat at receiver position is to be determined and the efficiency is also be varying at respective to change the given parameters of the system. conclusion part of each cases are as follows:-

As wind velocity increases, heat loss from receiver increases and receiver efficiency decreases. This is due to increase in Reynolds number and consequently increase in forced convection heat loss. So, wind velocity of air is to be minimum so we can achieve maximum efficiency rate. With increase in fluid inlet and outlet temperature, average surface temperature increases which increases the temperature difference and consequently the heat loss. So, with increase in inlet and outlet fluid temperature, heat loss increases and receiver efficiency decreases. With increases in ambient temperature, temperature difference between surface and ambient decreases, which decreases the heat loss and increases the receiver efficiency. With increases in ambient temperature from $25-35^{\circ} \mathrm{C}$, receiver efficiency increases from $62-85 \%$.

\section{SOFTWARE ANALYSIS}

Energy3D is a simulation-based engineering tool for designing green buildings and power stations that harness renewable energy to achieve sustainable development. Users can quickly sketch up a realistic-looking structure or import one from an existing CAD file, superimpose it on a map image (e.g., Google Maps or lot maps), and then evaluate its energy performance for any given day and location. Based on computational physics and weather data, Energy3D can rapidly generate time graphs (resembling data loggers) and heat maps (resembling infrared cameras) for in-depth analyses. Artificial intelligence is also used to support generative design, engineering optimization, and automatic assessment. At the end of the design, Energy3D allows users to print it out, cut out the pieces, and use them to assemble a physical scale model. Energy3D has been primarily developed to provide a simulated environment for engineering design to support science and engineering education and training 
from middle schools to graduate schools. As its simulation results are accurate and its user interfaces are friendly, it may also be used as an entry-level energy simulation tool for professionals. In the parabolic dish collector energy calculation by daily yield calculation and annually calculation are to be shown in this report.

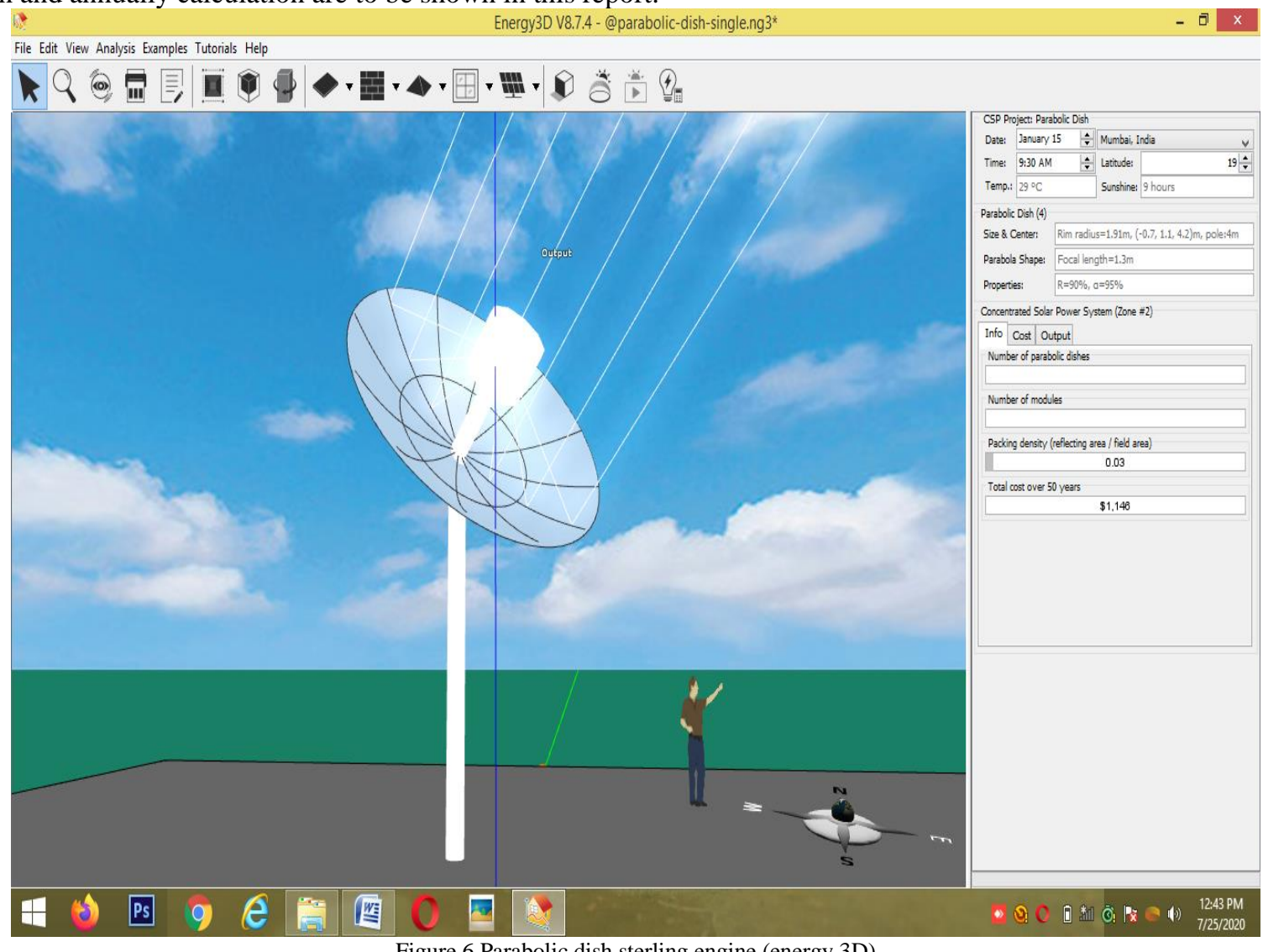

Figure 6 Parabolic dish sterling engine (energy 3D)

Below table shows the value of rim radius with respect to rim angle(from equation 5)

$$
\frac{f}{d_{c}}=\frac{1}{4 \tan (\varphi / 2)}
$$

By using this formula focal length consider to be $1.326 \mathrm{~m}$ and rim angle 71.57 degree for the external cavity receiver. Getting the collector diameter $3.82 \mathrm{~m}$ so the rim radius is $1.91 \mathrm{~m}$. that rim radius is to be utilised into the energy 3D software after putting all initial parameter for the Mumbai, Kolkata, Chennai, Amritsar location we analyse the energy analysis.

\section{SOFTWARE ANALYSIS RESULT}

Energy $3 \mathrm{~d}$ software is to be analyses the energy distribution in daily yield and annual yield contribution on parabolic dish. Set the input parameter for the parabolic dish i.e. rim radius, focal length, date, location ,latitude ,and time hours after consideration of this input parameters calculate energy distribution.

Here the effective rim radius is considered for the evaluation and carried out result on four location Mumbai, Chennai, Kolkata and Amritsar these four references are to considered for the east -west and north -south direction

Table 5 shows the yearly radiation of different cities of India

\begin{tabular}{|c|c|c|}
\hline Sr. No. & $\begin{array}{c}\text { Places } \\
\text { (City) }\end{array}$ & Yearly radiation (kwh) \\
\hline 1 & Mumbai & 2797.6 \\
\hline 2 & Kolkata & 2201.63 \\
\hline 3 & Chennai & 2952.3 \\
\hline 4 & Amritsar & 2827.12 \\
\hline
\end{tabular}




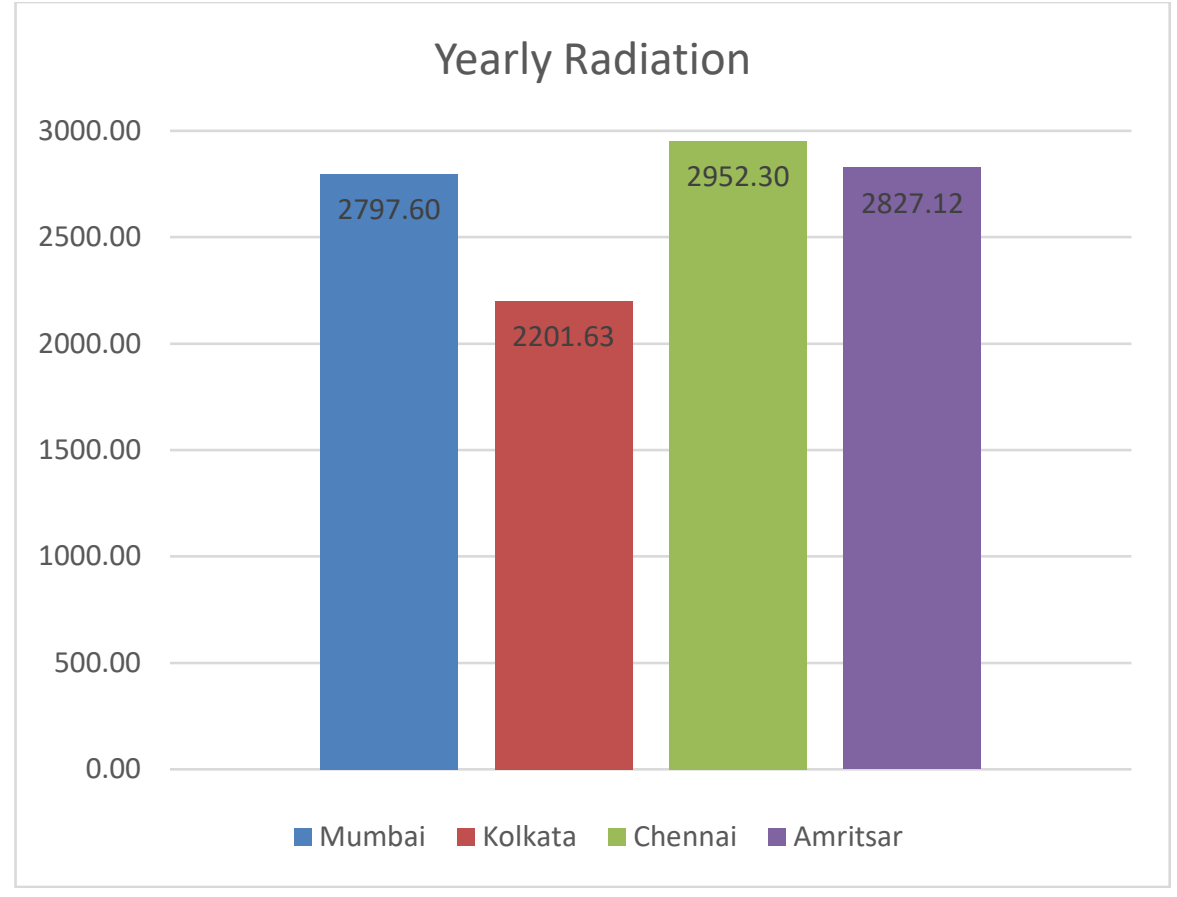

Figure 7 Annual Yield Energy Of Different Location In India

Table 6 shows the monthly variation respective cities

\begin{tabular}{|c|c|c|c|c|c|}
\hline Sr No. & Month & Mumbai & Kolkata & Chennai & Amritsar \\
\hline 1 & January & 290.78 & 212.35 & 218.86 & 177.32 \\
\hline 2 & February & 278.88 & 194.6 & 263.2 & 182.28 \\
\hline 3 & March & 303.8 & 249.24 & 332.01 & 234.98 \\
\hline 4 & April & 301.2 & 243.9 & 310.8 & 278.1 \\
\hline 5 & May & 305.35 & 241.49 & 299.46 & 313.41 \\
\hline 6 & June & 165.9 & 127.8 & 209.7 & 272.4 \\
\hline 7 & July & 69.44 & 98.89 & 196.54 & 231.26 \\
\hline 8 & August & 83.39 & 112.84 & 213.28 & 241.18 \\
\hline 9 & September & 152.4 & 119.7 & 207.6 & 245.7 \\
\hline 10 & October & 253.58 & 198.71 & 212.35 & 260.09 \\
\hline 11 & November & 277.2 & 195 & 193.8 & 212.7 \\
\hline 12 & December & 309.38 & 205.84 & 218.86 & 179.18 \\
\hline
\end{tabular}

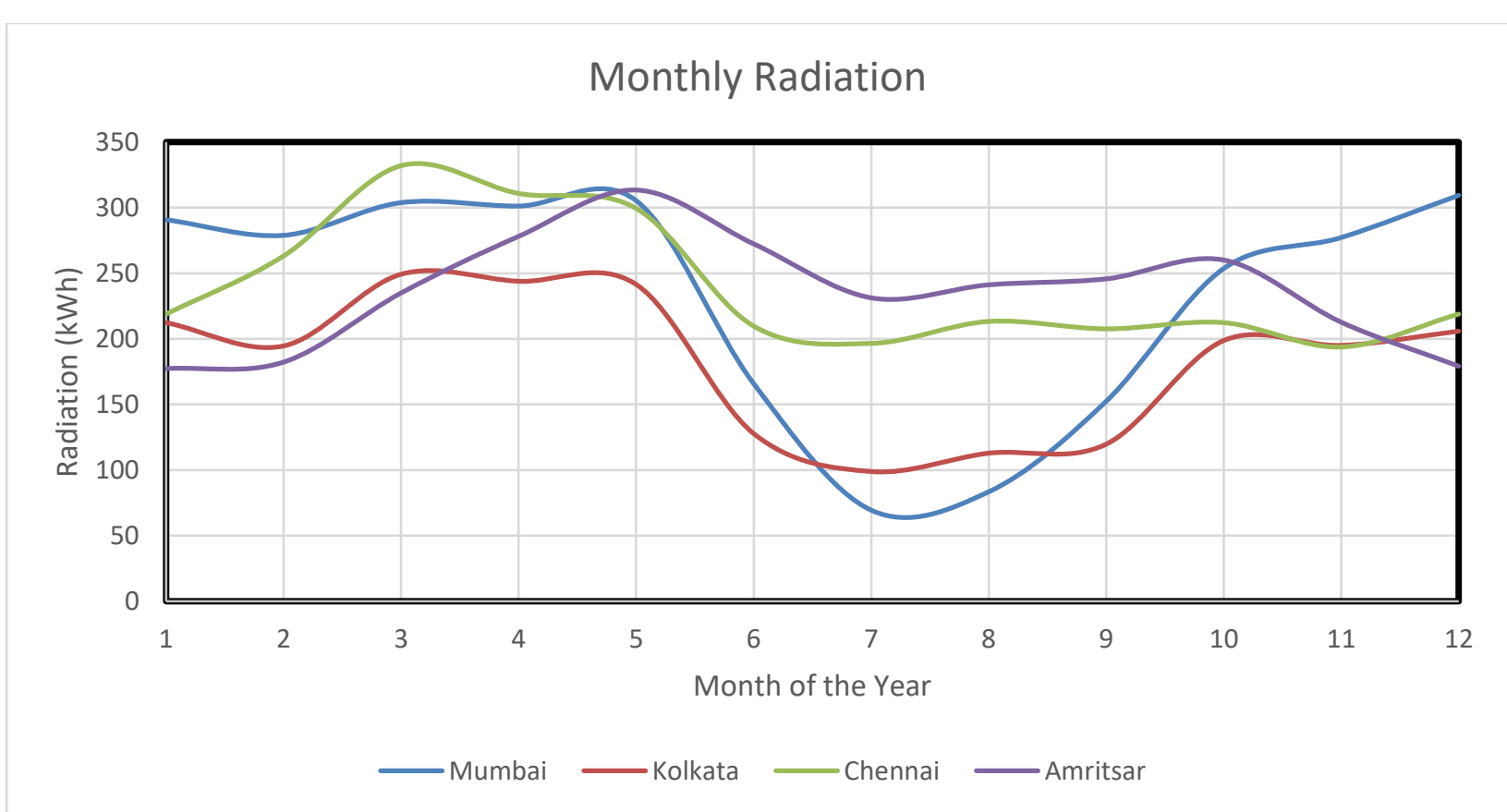

Figure 8 Monthly Yield Energy Analysis Of Different Location In India 
The focal region area affects both optical efficiency and the concentration ratio of the solar parabolic dish. solar radiation which are reflected from the concentrator to receiver section that time some heat loss are to be happened, in the form of convection, radiation and reflection remaining flux reaches toward the receiver and achieve maximum efficiency. Rim radius performs the work which is to be calculate the energy estimation by energy 3Dsoftware.Energy Analysis is done by both the cases daily yield and annual yield performance and observed the result of increasing the rim radius to achieve the maximum energy generation.So we can think about the plant location for certain cases as required by the energy 3Dsoftware.

\section{FUTURE SCOPE}

1. As Parabolic Dish (PD) is one of the most efficient Concentrating Solar Technology (CSP) technologies that can convert solar energy into thermal energy and electricity With highest efficiency and can able achieve up to $750^{\circ} \mathrm{C}$ temperature .

In this research we have done (PD) design, experimentation and Enery Analysis with the help of 3D software. To achive the maximum thermal efficiency of the solar receiver for a specific geometrical region irrespective of the solar radiation intensity more design modifications, improvement and research has to be done with respect to CFD, CAD \& CAM.

2. In this research we have observed that the increase in the rim radius is responsible to achieve the maximum energy generation. So by referring dimensional design data, suitability of any specific location could be predicted, studied and verified for maximum thermal efficiency achievement.

\section{REFERENCE}

[1] BillyAnak Sup, Mohd. Farid Zainudin, Tanti ZanariahShamsir Ali, Rosli Abu Bakar, Gan Leong Ming, "Effect of Rim Angle to the Flux Distribution Diameter in Solar Pa1rabolic Dish Collector”, Energy Procedia,Volume 68,2015,Pages 45-52,ISSN 18766102https://doi.org/10.1016/jegypro2015.03.231.

[2] Matthias Günther,RezaShahbazfar, “Solar Dish Technology” Institute for Electrical Engineering, Rational Energy Conversion, University of Kassel, WilhelmshöherAllee 73, 34121Kassel

[3] Saša R. Pavlovic and Velimir P. Stefanovic, "Ray Tracing Study of Optical Characteristics of the Solar Image in the Receiver for a Thermal Solar Parabolic Dish Collector"https://doi.org/10.1155/2015/326536

[4] Alarcón, J., Hortúa, J., \& Lopez G., A. 2013 Jul 30.” Design and construction of a solar collector parabolic dish for rural zones in Colombia.’TECCIENCIA. [Online] 7:14

[5] Ibrahim ladanmohammed, "Design and development of a parabolic dish Solar water heater" international journal of engineering research and Applications (ijera) issn: 2248-9622 www.ijera.com vol. 2, issue 1, jan-feb 2012, pp.822-830

[6] MohammadrezaSedighi, Ricardo Vasquez Padilla,MareeLake,Andrew Rose, Yee Yan Lim,Jeremy Paul Novak, Robert A. Taylor. (2020) “Design of hightemperature atmospheric and pressurised gas-phase solar receivers".A comprehensive review on numerical modelling and performance parameters. Solar Energy201,701-723

[7] YacobGebreyohannesa, AbenezerBekelea, PetrosGebraya,"Ray-Tracing Study for Optical Characterization of Solar-Concentrator Reflecting-Materials" Branna Journal of Engineering and Technology (BJET)Vol. 1, No. 1: March, 2019, pp.71 88

[8] "Material and Component Specifications Single Axis Tracked Parabolic Trough" parabolic trough collectors, by IT Power India,december 2015 ,Ministry of New and RenewableEnergyhttp://www.itpower.co.in/wp-content/uploads/2016/01/Final-Booklet-4-ParabolicTrough.pdf

[9] "Material and Component Specifications Fresnel Reflector Based Dish with Moving Focus (ARUN)",Under UNDP-GEF market development \& promotion of solar concentrator based process heat application in India Ministry of New and Renewable Energy Government of India December 2015,www.itpower.co.in

[10] Jan Kleissl, "Solar Energy Forecasting and Resource Assessment, Academic Press", 2013,Pageiv, ISBN 9780123971777 https://doi.org/10.1016/B978-0-12- 397177- 7.02001 http://www.sciencedirect.com/science/article/pii/B9780123971777020015

[11] Werner Weiss, "Potential of Solar Thermal in Europe", AEE - Institute for Sustainable Technologies Peter Biermayr, Vienna University of Technology

[12] RosnaniAffandi, MohdRuddin Ab Ghani, Chin Kim Ghan, LiawGeokPheng, The Impact of the Solar Irradiation, Collector and the Receiver to the Receiver Losses in Parabolic Dish System, Procedia - Social and Behavioral Sciences, Volume 195, (2015), Pages 2382-2390, ISSN 18770428https://doi.org/10.1016/jsbspro 2015.06.220

[13] Affandi, Rosnani, et al. "Performance Comparison for Parabolic Dish Concentrating Solar Power in High Level DNI Locations with George Town, Malaysia." Applied Mechanics and Materials, vol. 699, Trans Tech Publications, Ltd., Nov. 2014, pp. 570-576. Crossref, doi:10.4028/www.scientific.net/amm.699.570

[14] D. Howard and R. G. Harley, "Modeling of dish-Stirling solar thermal power generation," IEEE PES General Meeting, Providence, RI, 2010,pp.1-7

[15] Wendelin, Tim. "solTrace: A New optical Modeling Tool for Concentrating Solar Optics." Proceedings of the ASME 2003 International Solar Energy Conference.SolarEnergy.Kohala Coast, Hawaii, USA. March 15-18, 2003. Pp.253- 260.ASME.https://doi.org/10.1115/ISEC2003-44090

[16] Jafrancesco, D., Cardoso, J. P., Mutuberria, A., Leonardi, E., Les, I., Sansoni, P., Fontani, D. (2018, October 1). “Optical simulation of a central receiver system: Comparison of different software tools."Renewable and Sustainable Energy Reviews. Elsevier Ltdhttps://doi.org/10.1016/j.rser2018.06.028

[17] Hoffschmidt, B. et.al (2001). Romero, M., Stobbe, P., Te'llez, volumetric receiver technology. In: Proceedings of 5th Cologne Solar Symposium, Forschungsbericht 2001-10, DLR, Germany, pp.51-61Development ofceramic.

[18] Antonio, L. et.al (2011). Volumetric receivers in Solar Thermal Power Plants with Central Receiver System technology: A review. solar energy, 85 ,Issue:5,891-910

[19] Bello-Ochende, T et.al (2014). The efficiency of an open-cavity tubular solar receiver for a small-scale solar thermal Brayton cycle.EnergyConversion and Management, 84,457-470.

[20] Bader,R .Experimental and numerical heat transfer analysis of an air-based cavity- receiver for solar trough concentrators. J Sol Energy Eng 2012;134(2):021002-021002-8.

[21] Tobergte, David R. et.al (2014).Global Review of Solar Tower Technology. Journal of Chemical Information and Modeling, 53, Issue: 9, $1689-1699$.

[22] Singh,Rohit.et.al(2016).AnalyticalAnalysisforReceiverandItsProcessingforA

[23] $30 \mathrm{Kw}$ CL-CSP System at RGPV Bhopal. International Journal for Scientific Research \& Development, 04; Issue 03,1859-1864.

[24] Saxena, Harshit.et.al (2013). Computational Study on Estimating the Surface Heat Transfer Coefficient of Absorber Tube in Solar Parabolic Trough Collector. Applied Mechanics and Materials, 446-447,1546-1551. 
[25] Ortega, J.et.al (2008). Central receiver system solar power plant using molten salt as heat transfer fluid. Journal of Solar Energy Engineering, Transactions of the ASM E, 130; Issue3,245011-245016

[26] THERMINOL Heat Transfer Fluid.(2017).THERMINOL® $\quad$ 55HEATTRANSFER https://www.therminol.com/products/Therminol-55. [Accessed 30August2017].

[27] Kalogirou SA, Solar thermal collectors and applications, Prog Energy Combust Sci., 30(3), 2004,231-95.

[28] Kribus A, Kaftori D, Mittelman G, Hirshfeld A, Flitsanov Y, Dayan A; A miniature concentrating photovoltaic and thermal system, Energy Convers Manage, 47(20), 2006,3582-90.

[29] FeuermannD, Gordon JM, High-concentration photovoltaic designs based on miniature parabolic dishes, Solar Energy, 70(5),2001,423-30.

[30] Alaphilippe M, Bonnet S, Stouffs P, Low power thermodynamic solar energy conversion: coupling of a parabolic trough concentrator and an Ericsson engine, International Jounal of Thermodynamics, 10(1),2007,37-45

[31] Segal A, Epstein M, Optimized working temperatures of a solar central receiver. Solar Energy 75(6),2003,503-10.

[32] Palavras I, Bakos GC; Development of a low-cost dish solar concentrator and its application in zeolite desorption, Renewable Energy, 31(15),2006,242231.

[33] Robert Y. Ma, ( September 1993), Wind Effects on Convective Heat Loss From a Cavity Receiver for a Parabolic Concentrating Solar Collector, Sandia National Laboratories, New Mexico 87185,1993,1-65.

[34] Wu YC, Wen LC, Solar receiver performance of point focusing collector system, ASME winter annual meeting, San Francisco, CA,1978.

[35] vanitathakkar ,ankushdoshi "Performance Analysis Methodology for Parabolic Dish Solar Concentrators for Process Heating Using Thermic Fluid" https://www.researchgate.net/publication/336511709

[36] EvangelosBellos, ErionBousi, Christos Tzivanidis, SasaPavlovic "Optical and thermal analysis of different cavity receiver designs for solar dish"concentrators,Energy Conversion and Management:X ,Volume2, 2019, 100013, ISSN25901745,https://doi.org/10.1016/j.ecmx.2019.100013. (http://www.sciencedirect.com/science/article/pii/S259017451930011X)

[37] joseph stalin, maria jebamalai, “ Receiver Design Methodology for Solar Tower Plants" KTH school of industrial engineering and management SE-10044 stockholm august, 2016

[38] vanitathakkar, ankushdoshi, "Performance Analysis Methodology for Parabolic Dish Solar Concentrators for Process Heating Using Thermic Fluid" https://www.researchgate.net/publication/336511709

[39] C.E. Kennedy "Review of Mid-to High temperature solar selective absorber materials" national renewable energy laboratoryNREL/TP-520-31267 